\title{
Mudanças políticas recentes e competitividade no mercado internacional de soja
}

\author{
Luciano Menezes Bezerra Sampaio* \\ Yony Sampaio** \\ Ecio de Farias Costa***
}

Resumo: Não obstante haver perspectivas de expansão do mercado mundial, com aumento da participação do Leste Asiático, principalmente da China, há várias polêmicas como o uso da soja transgênica; as disputas comerciais no âmbito da $\mathrm{OMC}$ em relação à proteção agrícola; e os efeitos da implementação da ALCA para os três maiores exportadores e participantes da mesma. No período mais recente, destacam-se as últimas duas leis agrícolas dos EUA, que aumentaram os subsídios a seus produtores de soja, e a adoção, pelo Brasil e Argentina, em 1999 e 2002, respectivamente, de regimes de câmbio flutuante, ocasionando desvalorização de suas moedas. Analisam-se os efeitos das mudanças políticas recentes, através de um modelo de equilíbrio geral computável. As conclusões indicam que as desvalorizações das moedas do Brasil e da Argentina mais que compensaram o aumento dos subsídios americanos a seus produtores de soja, sendo o Brasil o maior beneficiário dessas mudanças. Para o Brasil, de modo particular, a expansão do mercado apresenta-se promissora,

*Professor Adjunto, Departamento de Economia e Curso de Pós-Graduação em Economia da UFPB. Doutor em Economia pela UFPE/ PIMES - Sorbonne/ Paris 1, 2004. lsamp@hotmail.com

**Professor Titular de Economia do Dept. de Economia/ PIMES, UFPE. Ph.D. em Economia pela Universidade da Califórnia, 1973. Pesquisador bolsista do CNPq. ysampaio@elogica.com.br

***Professor Adjunto do Dept. de Economia/ PIMES, UFPE. Ph.D. em Economia Agrícola, University of Georgia, 2001. ecio@yahoo.com 
uma vez que é o único exportador com possibilidades de expansão da produção em larga escala e apresenta custos competitivos.

Palavras-chave: mercado internacional de soja, mudanças políticas recentes, modelo de equilíbrio geral.

\section{Classificação JEL: Q17, F14}

Abstract: Although the world market seems to be expanding, with an increasing participation of the Asian East, mainly of China, it is still subject to much debate related to the use of genetic modified varieties, to commercial disputes within WTO due to agriculture protection, and to effects of ALCA's establishment, joining the three main exporters. In the short run, emphasis was given to the last two American agricultural bills which raised their subsidies to their soybean producers and the adoption by Brazil and by Argentine, in 1999 and 2002, respectively, of floating exchange systems, with drastic currency devaluation. The effects of the recent political changes are analyzed using a general equilibrium model. The conclusions indicate that currency devaluation in Brazil and Argentine more than compensated the increase in the American subsidies to its soybean producers, Brazil being mostly benefited; For Brazil, particularly, the world market expansion appears promising, since its the only exporter with the possibility of largely increasing its production and it has competitive costs.

Key words: Soybeans International market, recent political changes, general equilibrium model.

JEL Classification: Q17, F14

\section{Introdução}

O mercado internacional de soja caracteriza-se por domínio das exportações de três países: Brasil, Argentina e EUA. O Brasil destaca-se nas exportações tanto de grãos como de derivados (farelo e óleo de soja). Os EUA são os maiores exportadores de grãos, com pequena participação no comércio de derivados, e a Argentina especializou-se nas exportações de farelo e óleo de soja. 
Considerando o valor exportado do complexo soja, a partir de meados da década de 1990, observa-se a crescente participação do Brasil e da Argentina, em detrimento da parcela de mercado dos EUA que detinha média de $40 \%$ do valor mundial exportado de 1990 a 1998, e teve seu percentual reduzido, atingindo pouco mais de 30\%, em 2003 (Figura 1).

Figura 1 - Participação de Brasil, Argentina e EUA no valor das exportações mundiais de soja e derivados (em \%)

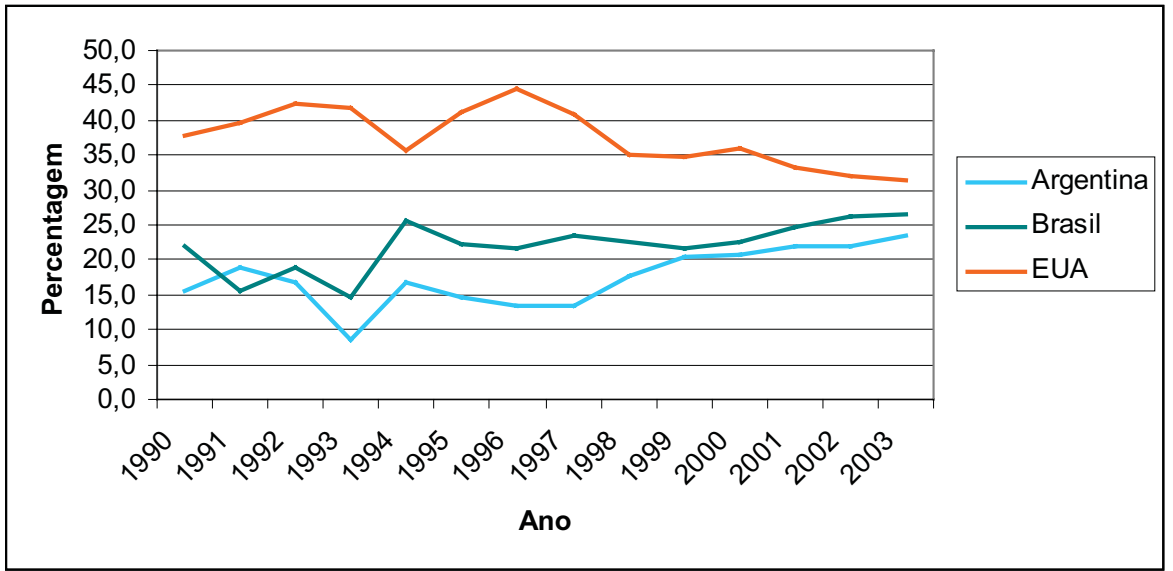

Fonte: dados de FAOSTAT (2004)

A dinâmica das participações de mercado desses países não esta definida. Para o futuro, controvérsias como a polêmica dos transgênicos e a posição contrária da UE a seu uso; os limites ao crescimento da produção nos países do Mercosul e nos EUA; a expansão do mercado mundial e o aumento participativo da China no mesmo; a agenda adotada pela Organização Mundial do Comércio (OMC) e a relutância dos países desenvolvidos a incluir a proteção agrícola no debate; e as negociações da ALCA $^{1}$; são pontos importantes para a definição das parcelas de mercado do Brasil e de seus concorrentes.

${ }^{1}$ Gurgel et al. (2002) utilizou o GTAP para analisar efeitos da ALCA e de acordo entre Mercosul e UE para o Brasil, realizando análises de variáveis como PIB, balança comercial e exportações do setor agrícola. Neste último caso, eles destacam o aumento percentual das exportações brasileiras de "outras culturas", categoria que inclui a soja e derivados, na versão 3 do modelo. 
Enquanto essas questões de perspectivas mais distantes não se definem, o centro das discussões sobre a competitividade e participação no mercado internacional de soja é o efeito de mudanças políticas ocorridas recentemente nos três países exportadores. Os EUA, através de suas últimas duas leis agrícolas, aumentaram os subsídios a seus produtores de soja. Brasil e Argentina adotaram, em 1999 e 2002, respectivamente, regimes de câmbio flutuante, com as desvalorizações de suas moedas contribuindo para aumento de suas competitividades no setor de soja, pelo menos no curto prazo.

Os efeitos da desvalorização para o Brasil foram mencionados em Lower (2002), que considerando o preço internacional da soja e a taxa de câmbio se mantendo nos patamares da época, fez previsões de manutenção das taxas de substituição entre área de pastagem que vem sendo convertida em plantação de soja e de ocupação de novas áreas com soja no Brasil, assim como manutenção da expansão das exportações do país para os próximos anos.

Na Argentina, o cenário político que levou à desvalorização de sua moeda (desvalorização de $70 \%$ do peso frente ao dólar em 2002) era de crise econômica, com o colapso do sistema bancário. Mesmo assim, o setor agrícola reagiu rapidamente e produtores de soja, semelhantemente aos brasileiros, foram beneficiados na medida em que já haviam realizado os gastos com insumos e, a receita, com as vendas realizadas posteriormente, foi bem maior em moeda local. Muitos produtores, após a desvalorização, também passaram a negociar o produto diretamente como moeda, adquirindo máquinas e insumos e "pagando-os" com mercadoria. As expectativas colocadas em relatório do USDA (Verdonk, 2003), para Argentina, são de expansão de mercado para 2003/04, após recorde de produção agrícola em 2002/03, acompanhada de aumento das exportações tanto em grãos como em derivados.

Nos EUA, as últimas duas leis agrícolas aumentaram os subsídios para seus produtores de soja. Na nova Lei - a Farm Bill de 2002 - os pagamentos diretos para produtores de soja foram ampliados, passando de US\$ 0,15 para US\$ 0,44 por bushel. Esses pagamentos passaram a ser específicos para a soja e baseados na área plantada e produtividade do período 1998/2001 (Coelho, 2002).

Brandão \& Lima (2002), em trabalho encomendado pelo Ministério da Agricultura e do Abastecimento brasileiro e pela Confederação Na- 
cional da Agricultura (CNA), analisaram, com base na nova lei agrícola, os efeitos dos subsídios americanos sobre o mercado internacional de soja, através de modelo econométrico, e concluíram que o suporte americano tem impacto significativo no comércio exterior, já que $50 \%$ do aumento da produção será exportado. Conclusões semelhantes foram apresentadas por Westcott \& Price (1999) que indicaram que o programa dos EUA tem o potencial de causar distorções na produção doméstica, nas exportações americanas e no comércio global.

O objetivo do presente trabalho é identificar os efeitos líquidos dessas três mudanças (desvalorização do Real e do Peso e aumento dos subsídios americanos) para as participações futuras de mercado dos principais exportadores de soja e derivadas, com maior ênfase para o Brasil. Para tanto, usa-se o modelo de equilíbrio geral computável do Global Trade Analysis Project (GTAP model), empregado em inúmeros estudos de comércio internacional, sobretudo em questões agrícolas.

Após esta breve introdução, discute-se, na seção 2, a estrutura básica do modelo utilizado e na seção 3 , sua operacionalização. Na seção 4, são expostos os resultados de médio prazo do modelo de equilíbrio geral computável. Em seguida, na 5, apresenta-se a validação do modelo, através das estatísticas de curto prazo. Por fim, a seção 6 traz as conclusões e discussões.

\section{O Modelo Teórico²}

O GTAP foi desenvolvido a partir da crescente demanda por análises quantitativas de políticas numa base global, devido à maior integração da economia mundial. Exemplos são as análises desenvolvidas a partir das negociações da Rodada Uruguai e as estimações de seus impactos sobre países, comércio internacional e bem-estar em todo o mundo. As análises das conseqüências para cada setor dependem da interação entre eles, uma vez que esses acordos afetam toda a economia mundial, e, portanto se faz necessário o emprego de modelos que captem a interação entre países, suas características individuais e dados para cada um deles ao nível de commodities.

${ }^{2}$ Descrição do modelo baseada em Hertel, 1997. 
Figueiredo et al. (2001) utilizaram o GTAP para analisar o impacto da ALCA e do acordo Mercosul-UE sobre a agricultura brasileira e européia, concluindo em resultados de crescimento para o Brasil com a formação dos dois blocos, sendo a agricultura principal responsável pelo bom resultado para o Brasil. Na base de dados da versão utilizada, a soja estava incluída na categoria "outros grãos" que sofreram expressivo aumento percentual de suas exportações.

Yu \& Frandsen (2002) analisaram o impacto da entrada da China na OMC para o mercado agrícola chinês, usando o GTAP. Especificamente para a soja, indicaram pequenas reduções em seu preço internacional, devido às reduções de tarifas para esse bem, além de efeitos internos ao mercado da China, como aumento das importações principalmente de derivados.

A idéia geral do modelo GTAP consiste num sistema de equações simultâneas que expressam as decisões dos agentes, simplificando o comportamento real, onde há uma sucessão de decisões. Essa sucessão pode ser entendida, de forma simplificada, iniciando-se com os preços domésticos, de exportação e mundiais. Os preços dos produtos dependem da elasticidade de transformação entre as vendas externas e domésticas. Cada atividade usa fatores fixos (capital e trabalho). Dados os preços dos produtos e insumos, e do trabalho (o salário), as firmas maximizam lucro e, assim, determinam a demanda por trabalho (L). Se o mercado de trabalho é perfeito, os salários e o equilíbrio entre oferta e demanda de trabalho se ajustam antes do emprego pleno ser atingido. A renda dos fatores, então, é distribuída para as instituições (famílias, firmas e governo), e atingem seus níveis finais após as transferências entre elas, como o recebimento dos impostos pelo governo e a redistribuição dessa receita para as famílias e firmas, assim como a distribuição de lucros. O valor da poupança é determinado por uma taxa de poupança constante para as famílias (que pode variar entre as camadas sociais) derivada da maximização da função utilidade. A poupança determina o nível total de investimento, sendo a alocação entre setores exógena. No lado da produção, a alocação entre mercado doméstico e exportador depende dos preços relativos doméstico e de exportação e da elasticidade de transformação. Esses fatores determinam a oferta doméstica e as exportações por bens. A partir daí, as importações e exportações, demanda e oferta por moeda estrangeira, decidem o câmbio, 
completando o ciclo com os novos preços domésticos, de exportação e de importação. Esse processo continua até a convergência do conjunto de preços (vetor de preços do equilíbrio geral) para valores que garantam o equilíbrio de todos os mercados.

A figura 2 mostra a integração das economias regionais. Para a produção, estabelece-se que cada setor produz um único produto. Os bens são valorados nos diversos preços, internos e externos. VOA $(i, r)$ representa o valor do produto, a preço dos agentes, ou seja, a quantia recebida pela firma da indústria $\boldsymbol{i}$, na região $r$, sendo determinada pelo produto do preço do bem por sua quantidade: $\boldsymbol{V O A}(i, r)=\boldsymbol{P S}(\boldsymbol{i}, r) * \mathbf{Q O}(i, r)$.

Esses pagamentos são precisamente exauridos pelos custos da firma, dada a hipótese de lucro zero assumida no modelo. Somando os impostos (subsídios) da produção, denotados por $\operatorname{PTAX}(\boldsymbol{i}, \boldsymbol{r})$, obtém-se o valor do produto, a preço de mercado, $\operatorname{VOM}(i, r),(\boldsymbol{P T A X}(i, r)+\operatorname{VOA}(i, r)=$ $\operatorname{VOM}(\boldsymbol{i}, \boldsymbol{r})$,$) . Esse valor é igual à soma das vendas domésticas, a preço$ de mercado, $\boldsymbol{V D M}(\boldsymbol{i}, \boldsymbol{r})$, com o valor das exportações de $\boldsymbol{i}$, da região $\boldsymbol{r}$ para todos os destinos, $\operatorname{VXMD}(i, r, s)$.

Adicionalmente, há a possibilidade de vendas ao setor internacional de transporte, $\boldsymbol{V S T}(\boldsymbol{i}, \boldsymbol{r})$, que devem cobrir as margens do transporte internacional.

Para converter os valores das exportações para valores FOB, é necessário adicionar as taxas de exportação, $\boldsymbol{X T A X}(\boldsymbol{i}, \boldsymbol{r}, \boldsymbol{s})$, que variam de acordo com o destino. A base de dados inclui as medidas protecionistas de comércio, específicas para cada destino a níveis desagregados de regiões e bens. A diferença dos valores de exportação, a preços mundiais, por destino, $\boldsymbol{V} \boldsymbol{X} \boldsymbol{W D}(\boldsymbol{i}, \boldsymbol{r}, \boldsymbol{s})$, e o valor CIF das importações, a preços mundiais, por fonte - VIWS $(i, r, s)$ - é exatamente a margem de transporte internacional: $\operatorname{VTWR}(i, r, s)=V X W D(i, r, s)-V I W S(i, r, s)$.

A esse ponto a commodity $i$ foi exportada da região $r$ e chegou a seu destino - região $\boldsymbol{s}$. Adicionando a tarifa de importação da região s, MTAX(i,r,s), tem-se o valor da importação da commodity $i$, a preços de mercado, por fonte. As importações das diferentes fontes são somadas para obter-se 0 valor das importações de $\boldsymbol{i}$, pela região $\boldsymbol{s}$, a preços de mercado.

As importações de $\boldsymbol{s}$ têm a participação das famílias privadas, do governo e das firmas, representadas, a preços de mercado, respectivamente, por $\operatorname{VIPM}(\boldsymbol{i}, \boldsymbol{s}), \operatorname{VIGM}(\boldsymbol{i}, \boldsymbol{s}), \operatorname{VIFM}(\boldsymbol{i}, \boldsymbol{s})$. De maneira análoga, 
as vendas domésticas da região $\boldsymbol{r}, \boldsymbol{V D M}(\boldsymbol{i}, \boldsymbol{r})$, também são distribuídas entre famílias, governo e firmas.

As firmas da região $s$ demandam insumos intermediários, a preços dos agentes, $\boldsymbol{V} F \boldsymbol{A}(\boldsymbol{i}, \boldsymbol{j}, \boldsymbol{s})$, que podem ser adquiridos no mercado doméstico, $\boldsymbol{V D F A}(\boldsymbol{i}, \boldsymbol{j}, \boldsymbol{s})$, ou importados da região $\boldsymbol{r}, \boldsymbol{V I F A}(\boldsymbol{i}, \boldsymbol{j}, \boldsymbol{s})$. Deduzindo-se as taxas sobre insumos, DFTAX(i,j,s) e IFTAX(i,j,s), obtêm-se os valores dos insumos, a preços de mercado, $\operatorname{VDFM}(\mathrm{i}, \mathrm{j}, \mathrm{s})$ e $\operatorname{VIFM}(\mathrm{i}, \mathrm{j}, \mathrm{s})$ :

$\operatorname{VDFM}(i, j, s)=\operatorname{VDFA}(i, j, s)-\operatorname{DFTAX}(i, j, s)$

$\operatorname{VIFM}(i, j, s)=\operatorname{VIFA}(i, j, s)-\operatorname{IFTAX}(i, j, s)$

As firmas também demandam serviços de bens não comercializáveis, tratados no modelo como bens de dotação (o que inclui, na base de dados, terra, trabalho e capital). Deduzindo as taxas da dotação $\boldsymbol{i}$ usada na indústria $\boldsymbol{j}, \boldsymbol{E} \boldsymbol{T A X}(\boldsymbol{i}, \boldsymbol{j}, \boldsymbol{s})$, do valor da demanda da firma, a preços dos agentes, obtém-se essa demanda a preços de mercado: $\operatorname{VFM}(i, j, s)=\operatorname{VFA}(i, j, s)-\operatorname{ETAX}(i, j, s)$.

A condição de lucro zero significa que as receitas das firmas, $\boldsymbol{V O A}(\boldsymbol{j}, \boldsymbol{s})$, são exauridas com os gastos, $\boldsymbol{V F A}(\boldsymbol{i}, \boldsymbol{j}, \boldsymbol{s})$, sejam eles com bens comercializáveis (insumos intermediários, por exemplo), ou dotações (fatores primários de produção).

As famílias têm como fonte de renda, as remunerações das dotações sejam elas perfeitamente móveis, gerando o mesmo retorno em todo o mercado, ou imóveis que apresentam retornos diferentes em cada região (como terra agrícola). Já, as aquisições das famílias, a preço dos agentes, $\boldsymbol{V P A}(\boldsymbol{i}, \boldsymbol{s})$, são divididas entre compras de produtos domésticos, VDPA $(\boldsymbol{i}, \boldsymbol{s})$, e importados, VIPA(i,s), ambos a preços dos agentes. Deduzindo-se as respectivas taxas sobre os produtos domésticos e importados, $\operatorname{DPTAX}(i, s)$ e IPTAX $(i, s)$, obtêm-se o valor das aquisições familiares, a preços de mercado: $\operatorname{VDPM}(i, s)=\operatorname{VDPA}(i, s)-\operatorname{DPTAX}(i, s)$ $e \operatorname{VIPM}(i, s)=\operatorname{VIPA}(i, s)-\operatorname{IPTAX}(i, s)$.

De forma similar, chega-se às aquisições do Governo: $\operatorname{VDGM}(i, s)=$ $\operatorname{VDGA}(i, s)-\operatorname{DGTAX}(i, s)$ e $\operatorname{VIGM}(i, s)=\operatorname{VIGA}(i, s)-\operatorname{IGTAX}(i, s)$. 
Figura 2 - Economia multirregional aberta

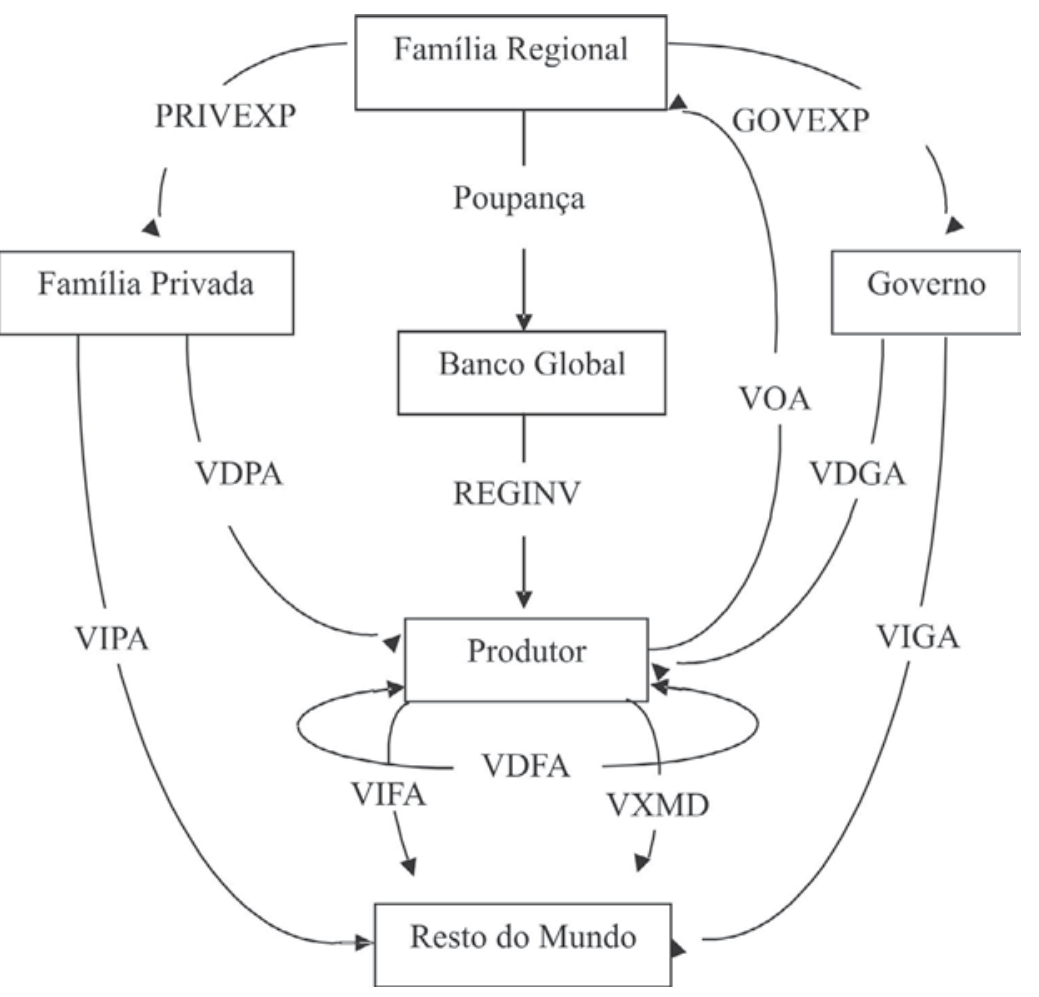

Fonte: Hertel, 1997

Ao invés de incorporar todos os impostos / subsídios observados, utiliza-se a abordagem de comparar valores de uma dada transação, a preços de mercado, e a preços mundiais. A discrepância entre o que as famílias recebem por seu trabalho ofertado e o valor dessa oferta, a preços de mercado, é o imposto sobre a renda. Alternativamente podem-se expressar esses impostos sobre a receita como impostos ad valorem no preço das dotações. De forma semelhante são tratados os demais tipos de impostos e subsídios da economia: impostos primários sobre as firmas; sobre os bens consumidos pelas famílias; sobre as compras das firmas pelos bens comercializáveis; e os impostos sobre o comércio.

Os setores Globais do modelo concluem sua estrutura. O setor de transporte produz o serviço responsável pela diferença entre os preços FOB e CIF para um bem particular transportado por uma rota especí- 
fica: $\operatorname{VTWR}(i, r, s)=V I W S(i, r, s)-V X W D(i, r, s)$. O "Banco Global” é o intermediário entre a poupança global e investimentos. Pela lei de Walras, se todos os outros mercados estão em equilíbrio, e se todas as firmas têm lucro zero e as famílias respeitam suas restrições orçamentárias, então o investimento global deve se igualar à poupança global.

Embora as relações contábeis descritas até aqui sejam expressas em valores, como os métodos de resolução matemática utilizados pelo GTAP são sistemas linearizados, é mais atrativo expressar os componentes comportamentais do modelo em termos de variações percetuais.

A Figura 3 mostra, em maiores detalhes, o comportamento das firmas, destacando suas tecnologias em cada indústria do modelo, através da árvore de produção.

Figura 3 - Estrutura da produção no GTAP

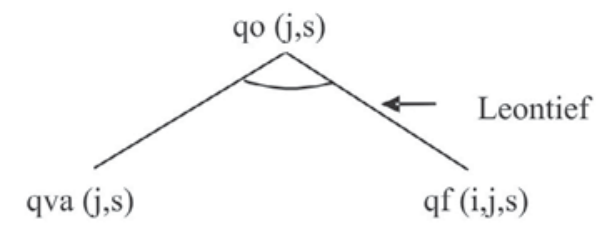

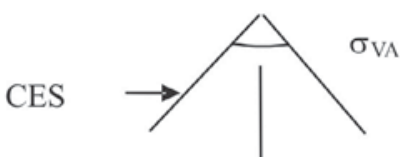

Terra Trabalho Capital qfe $(i, j, s)$

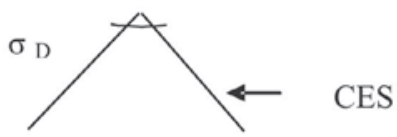

Domestico Estrangeiro qfd $(\mathrm{i}, \mathrm{j}, \mathrm{s}) \quad$ qfm $(\mathrm{i}, \mathrm{j}, \mathrm{s})$

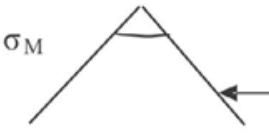

CES

Fonte: Hertel, 1997 
A produção da firma utiliza fatores primários e intermediários, sendo que estes últimos podem ser produzidos domesticamente ou importados. A combinação de fatores primários e intermediários é do tipo Leontief, não existindo substitutibilidade entre eles no modelo GTAP. Considera-se elasticidade de substituição constante (CES) entre os fatores intermediários domésticos e importados e ainda a hipótese de Armington para diferenciar por origem os insumos importados (Hertel, 1997; Figueiredo et al., 2001).

Do lado do consumidor, o comportamento familiar é governado por uma função utilidade agregada, especificada através do consumo privado, das compras governamentais e da poupança. A função utilidade é um caso especial da função Stone-Geary. A família dispõe da renda regional total de acordo com a função utilidade per capita Cobb-Douglas, especificada sobre as três formas de demanda final: gastos privados das famílias, gastos governamentais e poupança:

$\mathrm{U}=\mathrm{K}^{*} \mathrm{CP}^{\theta \mathrm{cp} *} \mathrm{CG}^{\theta \mathrm{cg} *} \mathrm{~S}^{\theta \mathrm{cs}}$,

em que $U$ é o nível de utilidade total em cada região $\mathrm{K}$, e $\theta$ o parâmetro da função. A maximização dessa função utilidade determina a alocação da renda em cada região, entre os três fatores de demanda (Hertel, 1997; Gurgel et al., 2002).

No fechamento padrão do modelo, cada uma dessas áreas representa uma participação constante da renda total. O fechamento econômico discute a determinação do investimento agregado. O GTAP não engloba políticas macroeconômicas e fenômenos monetários, que geralmente explicam o investimento. Como esse modelo não é intertemporal nem seqüencial no tempo para obter uma série de equilíbrios temporais, os investimentos não afetam a capacidade produtiva das indústrias (regiões) no período seguinte. Entretanto, considera-se no GTAP, uma realocação de investimentos entre regiões que afeta a produção e o comércio a partir de seus efeitos na demanda final. Para garantir que a demanda global por poupança se iguale à demanda global por investimentos no equilíbrio é que foi criado o "banco global" que recebe a poupança e distribui o montante, na forma de investimentos, entre as regiões. 


\section{Operacionalização do Modelo}

Nesse trabalho utiliza-se a versão $5^{3}$ que tem como ano base, 1997, para análise do mercado de soja. A Tabela 1 mostra as agregações das regiões e dos bens escolhidas. As 66 regiões do GTAP foram combinadas em 8 agregações: Brasil, Argentina e EUA (países exportadores), e União Européia (UE), China, Leste Asiático, América Latina e Resto do Mundo (importadores de soja). Os 57 setores da economia foram agregados em 6 categorias: soja em grão, derivados de soja, produção de carnes de frango e porco (principal destino do farelo de soja), outros alimentos, outros bens primários, manufaturados e serviços.

As desvalorizações foram aproximadas no modelo GTAP pela aplicação simultânea de subsídio à exportação e tarifa de importação ${ }^{4}$ O Brasil, em 1999, e a Argentina, em 2002, adotaram o regime de câmbio flutuante em suas moedas, causando desvalorizações acentuadas num curto período de tempo, o que pode resultar em ganhos de competitividade, em relação aos EUA, no mercado internacional de soja ${ }^{5}$. A relação do Real e do Peso para o dólar americano, que era de 1:1, em 1999, oscilando em 1:3, em 2004. Ou seja, desvalorização desse porte geralmente torna o país mais competitivo no mercado exportador. No caso do mercado da soja, Brasil e Argentina deveriam conquistar parcela do mercado exportador americano.

A intensidade dessas mudanças é determinada pela variação percentual das moedas desvalorizadas em relação ao dólar para o mesmo período. Os subsídios correspondem à apreciação do dólar frente à moeda local, sendo de $72 \%$ para o Brasil e de $74 \%$ para a Argentina. As tarifas de importação correspondem à depreciação das moedas locais frente ao dólar, sendo de $41 \%$ e $42 \%$ para Brasil e Argentina, respectivamente. As apreciação e depreciação, calculadas acima, baseiam-se

\footnotetext{
${ }^{3}$ Versão cedida pelo Centre de coopération internationale en Recherche Agronomique pour le Développement - CIRAD.

${ }^{4}$ Aproximações citadas em Grennes, 1984 e Houck, 1986, e utilizadas para o GTAP em Costa (2001).

${ }^{5}$ Bertrand (2001) cita, entre os fatores de competitividade de uma região, a competitividade preço que reflete a política cambial adotada por um país. Em geral, a desvalorização da moeda melhora o saldo comercial a médio prazo, com possível tendência negativa a curto prazo, dependendo da composição de importados do setor (Caves et al., 2001).
} 
nas mudanças dos câmbios reais, entre 1998 e 2002, reportadas por IPEA (2004) para o Brasil e por Indicadores Econômicos - Ministério de Economia da República da Argentina (2004).

Tabela 1 - Agregações regional e de bens

\begin{tabular}{|c|c|}
\hline Agregação regional & Agregação dos bens \\
\hline Brasil & $\begin{array}{l}\text { Soja em grão } \\
\text { Inclui oleaginosos em geral }\end{array}$ \\
\hline Estados Unidos (EUA) & $\begin{array}{l}\text { Derivados de soja } \\
\text { Inclui óleo e farelo de soja e de } \\
\text { outras oleaginosas como girassol }\end{array}$ \\
\hline $\begin{array}{l}\text { União Européia (UE) } \\
16 \text { países europeus }\end{array}$ & $\begin{array}{l}\text { Produção carnes } \\
\text { Principalmente carne suína e de } \\
\text { frango etc }\end{array}$ \\
\hline $\begin{array}{l}\text { China } \\
\text { Inclui Hong Kong } \\
\text { Leste Asiático }\end{array}$ & $\begin{array}{l}\text { Outros alimentos } \\
\text { Todos os demais, incluindo trigo, } \\
\text { arroz, açúcar, vegetais, frutas etc }\end{array}$ \\
\hline $\begin{array}{l}13 \text { países (Japão, Coréia, Tailândia, } \\
\text { etc) }\end{array}$ & $\begin{array}{l}\text { Outros produtos primários } \\
\text { Inclui combustível, minerais etc }\end{array}$ \\
\hline $\begin{array}{l}\text { América Latina } \\
9 \text { países (México, Colômbia, } \\
\text { Venezuela, etc) }\end{array}$ & $\begin{array}{l}\text { Manufaturados } \\
\text { Produtos têxteis, couro, madeira, } \\
\text { petróleo, metais etc }\end{array}$ \\
\hline $\begin{array}{l}\text { Resto do Mundo } \\
23 \text { países (entre eles, Canadá) }\end{array}$ & $\begin{array}{l}\text { Serviços } \\
\text { Água, gás, construção, transporte } \\
\text { etc }\end{array}$ \\
\hline
\end{tabular}

Fonte: a partir do GTAP

A incorporação dos subsídios americanos para os produtores de soja é feita de forma direta. Os subsídios aos produtores americanos de soja aumentaram significativamente, a partir de 1999. Nesse ano ocorreu a inclusão da soja no programa de Pagamentos Diretos do governo americano, baseados em área plantada e produtividade anteriores. A implementação do Farm Security and Rural Investments Act - FSRIA 2002, mais recente lei agrícola americana que estabeleceu as regras de 2002 a 2007, manteve a soja nesse programa, além de introduzir os Counter Cyclical 
Payments que beneficiam os produtores de soja em períodos de preços baixos e baseiam-se nas quantias colhidas e produtividades passadas.

Além dessas duas formas de subsídios, introduzidas recentemente para a soja, há ainda os Marketing Loans que cobrem a diferença entre os preços alvo (Loan Rate) e os preços de mercado ao produtor, caso estes últimos sejam inferiores aos primeiros (Tabela 2). Brandão \& Lima (2002) citaram Westcott \& Price (2001) e OECD (2000) para apontar que os Marketing Assistance Loan Program produzem efeitos nos preços e comércio mundial.

No modelo, os subsídios americanos são aplicados diretamente à produção, sendo calculado o aumento médio nos preços recebidos pelos produtores entre 2002 e 2004, vistos na Tabela 2, o que corresponde a $13 \%$ de subsídio sobre a produção.

Tabela 2 - Subsídios americanos aos produtores de soja, em US\$/bushel

\begin{tabular}{|c|c|c|c|c|c|c|c|}
\hline & (1) & (2) & (3) & $\begin{array}{c}(4)= \\
(1)-(2) *(3)\end{array}$ & (5) & (6) & $\begin{array}{c}(7)= \\
(4)+(5)+(6) \\
\end{array}$ \\
\hline Ano & $\begin{array}{l}\text { Loan } \\
\text { Rate }\end{array}$ & $\begin{array}{l}\text { Producer } \\
\text { Price* }^{*}\end{array}$ & $\begin{array}{l}\text { Fator } \\
\text { ajuste } \\
(\%)^{* *}\end{array}$ & $\begin{array}{l}\text { Marketing } \\
\text { Loan } \\
\text { Payments }\end{array}$ & $\begin{array}{l}\text { Pagamentos } \\
\text { Diretos } * * *\end{array}$ & $\begin{array}{l}\text { Counter } \\
\text { cyclical } \\
\text { payments }\end{array}$ & $\begin{array}{l}\text { Recetia produtor } \\
\text { acima do } \\
\text { Loan Rate }\end{array}$ \\
\hline 1998 & 5,26 & 4,93 & 0,98 & 0,43 & 0,00 & 0,00 & 0,43 \\
\hline 1999 & 5,26 & 4,63 & 0,95 & 0,86 & 0,14 & 0,00 & 1,00 \\
\hline 2000 & 5,26 & 4,54 & 0,91 & 1,13 & 0,15 & 0,00 & 1,28 \\
\hline 2001 & 5,26 & 4,38 & 0,94 & 1,14 & 0,15 & 0,00 & 1,29 \\
\hline 2002 & 5,00 & 5,53 & 0,94 & - & 0,44 & 0,36 & 0,80 \\
\hline 2003 & 5,00 & 7,25 & 0,94 & - & 0,44 & 0,36 & 0,80 \\
\hline 2004 & 5,00 & $5,70-6,70$ & 0,94 & - & 0,44 & 0,36 & 0,80 \\
\hline
\end{tabular}

* valores observados até 2003 e estimado para 2004; USDA, 2004;

** De Brandão e Lima (2002), fator que considera que o contrato é fechado ao menor preço de mercado da colheita.

*** De Brandão e Lima (2002), Programa para oleaginosos antes de 2001 e FSRIA, a partir de 2002.

Fonte: a partir de Brandão e Lima, 2002 e USDA, 2004

Desta forma, foram realizados três cenários de acordo com a ordem cronológica das mudanças ocorridas no mercado e ainda um último cenário, no qual se eliminam os subsídios americanos, dada uma possível disputa dos países do Mercosul contra os EUA, junto a OMC (Tabela 3). 
A depreciação dos preços internacionais da soja, simultaneamente ao aumento dos subsídios americanos, levou o Brasil e a Argentina, no início desta década, a analisarem uma possível disputa contra os EUA, na OMC, para a eliminação de seus subsídios, principalmente a parcela de Marketing Loan Assistance, considerados distorcidos (caixa laranja) pela entidade. Brandão e Lima (2002) recomendaram a abertura de Painel, evidenciando essa atitude. Mas, o recente aumento dos preços, a partir de 2002, com a forte demanda por importações (principalmente da China), fizeram os subsídios concentrarem-se nos Counter Payments e Pagamentos Diretos, considerados desvinculados (decoupled) da produção, ou seja, que não causam, ou causam em grau reduzido, efeitos sobre o mercado exportador.

Tabela 3 - Resumo das características dos cenários

\begin{tabular}{cccc}
\hline Cenários & $\begin{array}{c}\text { Inclusão subsídios } \\
\text { americanos }\end{array}$ & $\begin{array}{c}\text { Desvalorização } \\
\text { do Real }\end{array}$ & $\begin{array}{c}\text { Desvalorização } \\
\text { do Peso }\end{array}$ \\
\hline 1 & $\mathrm{X}$ & - & - \\
2 & $\mathrm{X}$ & $\mathrm{X}$ & - \\
3 & $\mathrm{X}$ & $\mathrm{X}$ & $\mathrm{X}$ \\
4 & - & $\mathrm{X}$ & $\mathrm{X}$ \\
\hline
\end{tabular}

\section{Resultados}

Analisam-se as alterações na produção, exportação e preços dos mercados de grão de soja e derivados para os quatros cenários, com o intuito de identificar a participação de cada uma das mudanças ocorridas no efeito final do mercado de soja e, no caso do último cenário, os efeitos da eliminação dos subsídios americanos. Por fim, enfatizam-se as variações nas exportações brasileiras de soja para seus principais destinos.

\section{Cenário 1}

Caso a imposição dos subsídios americanos não fosse seguida pelas desvalorizações das moedas brasileira e argentina, os ganhos na produção de grãos $(13,46 \%)$, e de derivados de soja $(6,16 \%)$ dos EUA, refletiriam mais negativamente na produção de grãos do Brasil $(-3,41 \%)$ que 
na da Argentina (-1,83\%) e causariam efeitos equivaletnes (-1\%) para a produção de derivados dos dois países (Tabela 4).

No mercado exportador, o aumento percentual para os EUA seria ainda mais expressivo; de $24,78 \%$ para grão e $18,32 \%$ para derivados. As exportações de Brasil e Argentina seriam afetadas de forma semelhante com variações negativas, da ordem de $14 \%$ e $3 \%$ para grãos e derivados, respectivamente.

Tabela 4 - Variações percentuais na produção, exportação e preços da soja e derivados para Brasil, Argentina e EUA, cenário 1

\begin{tabular}{llll}
\hline & Produção & Exportação & $\begin{array}{l}\text { Preços de } \\
\text { exportação }\end{array}$ \\
\hline Brasil & & & $-0,58$ \\
Grãos & $-3,41$ & $-13,92$ & $-0,39$ \\
$\quad$ Derivados & $-0,99$ & $-2,84$ & $-0,76$ \\
Argentina & & & $-0,63$ \\
$\quad$ Grãos & $-1,83$ & $-13,38$ & $-10,20$ \\
$\quad$ Derivados & $-1,11$ & $-2,72$ & $-5,74$ \\
EUA & 13,48 & 24,78 & \\
$\quad$ Grãos & 6,16 & 18,32 & \\
$\quad$ Derivados & & &
\end{tabular}

Fonte: cálculos da pesquisa

Os subsídios reduziriam os preços das exportações americanas de grão em 10,20\% e dos derivados, em 5,74\%. O impacto nos preços de exportação do Brasil e da Argentina seria mínimo: menor que 1\% para ambos os produtos, o que questiona a hipótese levantada pelos países do Mercosul de responsabilizar os subsídios americanos pela queda dos preços internacionais dos produtos de soja. Os resultados dos outros cenários corroboram a idéia de que são as políticas de cada país que afetam, em maior grau, os seus próprios preços de exportação dos produtos de soja. Assim, a queda nos preços brasileiros de exportação seria influenciada principalmente pela desvalorização do real. 


\section{Cenário 2}

Retratam-se os efeitos simultâneos da inclusão dos subsídios americanos para soja e da desvalorização do Real, ambos ocorridos em 1999 (Tabela 5). A Argentina tem suas produções de soja e derivados reduzidas em quase $6 \%$. O Brasil teria maior benefício na produção de derivados enquanto os EUA na de grãos.

No mercado exportador, Brasil obteria os maiores ganhos, com aumento de 20,56\% das exportações de grão e 46,74\% nas exportações de derivados. Os EUA teriam aumento de $24,9 \%$ para grãos e $16,79 \%$ para derivados. Já as exportações argentinas teriam queda expressiva.

Tabela 5 - Variações percentuais na produção, exportação e preços da soja e derivados para Brasil, Argentina e EUA, cenário 2

\begin{tabular}{llll}
\hline & Produção & Exportação & $\begin{array}{l}\text { Preços de } \\
\text { exportação }\end{array}$ \\
\hline Brasil & & & \\
$\quad$ Grãos & 3,90 & 20,56 & $-11,29$ \\
$\quad$ Derivados & 11,46 & 46,74 & $-13,51$ \\
Argentina & & & \\
$\quad$ Grãos & $-5,76$ & $-25,66$ & 0,99 \\
$\quad$ Derivados & $-5,83$ & $-14,53$ & 1,17 \\
EUA & & & \\
$\quad$ Grãos & 13,27 & 24,95 & $-11,64$ \\
$\quad$ Derivados & 5,63 & 16,79 & $-7,25$ \\
\hline
\end{tabular}

Fonte: cálculos da pesquisa

Os preços das exportações de grão aumentariam levemente para a Argentina (1\%) e cairiam mais que $11 \%$ para Brasil e EUA. Já os preços dos derivados também subiriam em aproximadamente $1 \%$ para a Argentina, enquanto cairiam em $13,51 \%$ para as exportações brasileiras e em $7,25 \%$ para as americanas.

\section{Cenário 3}

A desvalorização do Peso, ocorrida em 2002, somada às políticas anteriores, indica a recuperação da competitividade argentina no mer- 
cado de soja, principalmente para os derivados, cujas exportações são especialidade do país. Sua produção de grãos, assim como nos outros cenários, sofre pequenas variações. Em contrapartida, para derivados, eleva-se em $11 \%$. (Tabela 6).

Os EUA aumentam mais a produção de grãos (14\%) enquanto o Brasil a de derivados (7\%). Contudo, ressalta-se que o Brasil é o único dos três países com grande quantidade de área para expansão da produção de soja.

Tabela 6 - Variações percentuais na produção, exportação e preços da soja e derivados para Brasil, Argentina e EUA, cenário 3

\begin{tabular}{llll}
\hline & Produção & Exportação & $\begin{array}{l}\text { Preços de } \\
\text { exportação }\end{array}$ \\
\hline Brasil & 0,54 & 13,80 & $-9,98$ \\
$\quad$ Grãos & 6,76 & 34,61 & $-12,43$ \\
$\quad$ Derivados & 1,25 & $-0,60$ & $-5,99$ \\
Argentina & 11,35 & 28,82 & $-10,20$ \\
$\quad$ Grãos & & & \\
$\quad$ Derivados & 14,08 & 28,54 & $-2,31$ \\
EUA & 3,87 & 10,28 & $-2,35$ \\
$\quad$ Grãos & &
\end{tabular}

Fonte: cálculos da pesquisa

As exportações acompanham os efeitos da produção: para grãos, pequenas variações para a Argentina e aumentos expressivos para Brasil e EUA, tendo, este último, os melhores resultados. Para os derivados, todos os três aumentariam suas exportações, com destaque para Brasil e Argentina. Os preços das exportações para os três países caem entre 7 e $13 \%$, confirmando a queda que vinha ocorrendo até 2003 , antes do aumento na demanda mundial.

\section{Cenário 4}

Apesar da improvável eliminação dos subsídios americanos para seus produtores de soja, uma vez que nos últimos anos, eles concentraram-se em categorias tidas como não vinculadas à produção, esse ce- 
nário busca ratificar a atitude dos países do Mercosul em não entrarem com disputa na OMC contra os EUA.

A Tabela 7 mostra que, em termos de produção do complexo soja, Brasil e Argentina teriam ganhos para os derivados (8\% e $12,42 \%$ respectivamente). Para os grãos, o Brasil teria aumento de $4,84 \%$ e a $\mathrm{Ar}$ gentina, de cerca de $3 \%$.

No mercado exportador, os efeitos seriam mais significativos, com destaque para o Brasil: seu crescimento chegaria a 31,05\% para grãos e $38,20 \%$ para os derivados. Para a Argentina, as taxas seriam de 13,86\% e $31,50 \%$, para grãos e derivados, respectivamente.

Os EUA teriam suas exportações reduzidas de 2,59\% e observariam redução de 6,92\% para os derivados. Os preços das exportações cairiam para todos os três países, com maior impacto para os derivados brasileiros $(12,43 \%)$ e menor para as exportações americanas de grãos $(2,31 \%)$.

Tabela 7 - Variações percentuais na produção, exportação e preços da soja e derivados para Brasil, Argentina e EUA, cenário 4

\begin{tabular}{llll}
\hline & Produção & Exportação & $\begin{array}{l}\text { Preços de } \\
\text { exportação }\end{array}$ \\
\hline Brasil & 4,84 & 31,05 & $-9,98$ \\
$\quad$ Grãos & 8,00 & 38,20 & $-12,43$ \\
$\quad$ Derivados & & & \\
Argentina & 3,41 & 13,86 & $-5,99$ \\
$\quad$ Grãos & 12,42 & 31,50 & $-10,20$ \\
$\quad$ Derivados & & & \\
EUA $\quad 0,23$ & $-2,59$ & $-2,31$ \\
$\quad$ Grãos & $-2,00$ & $-6,92$ & $-2,35$ \\
$\quad$ Derivados & &
\end{tabular}

Fonte: cálculos da pesquisa

\section{Exportações brasileiras por destino}

A Tabela 8 mostra as exportações do Brasil por destino, para os quatro cenários. O aumento dos subsídios americanos causa maior impacto nas exportações brasileiras para a China, América Latina e Leste Asiático; importantes importadores dos EUA. Com destino para a UE, principal importador de farelo de soja do Brasil, os subsídios america- 
nos causam queda brasileira das exportações de grãos de $11,66 \%$, mas de apenas $0,94 \%$ para os derivados.

A desvalorização do Real restabeleceu a competitividade brasileira no mercado de soja, proporcionando variações positivas das exportações do país para todos os destinos, com destaque para a UE. Ressaltase o aumento superior a $40 \%$ das exportações de derivados para todos os destinos.

Tabela 8 - Variação percentual nas exportações do Brasil, de grãos e derivados de soja, por destino, em diferentes cenários

\begin{tabular}{|c|c|c|c|c|c|c|c|c|}
\hline & \multicolumn{4}{|c|}{$\begin{array}{c}\text { Exportações de Grãos } \\
\text { Cenários }\end{array}$} & \multicolumn{4}{|c|}{$\begin{array}{c}\text { Exportações de Derivados } \\
\text { Cenários }\end{array}$} \\
\hline & 1 & 2 & 3 & 4 & 1 & 2 & 3 & 4 \\
\hline \multicolumn{9}{|l|}{ Destinos } \\
\hline $\mathrm{EU}$ & $-11,66$ & 22,18 & 14,70 & 28,52 & $-0,94$ & 48,85 & 36,80 & 37,93 \\
\hline China & $-20,35$ & 11,06 & 4,84 & 29,97 & $-3,93$ & 40,99 & 29,83 & 34,54 \\
\hline Leste Asiático & $-17,55$ & 17,89 & 10,28 & 32,61 & $-4,02$ & 46,08 & 33,30 & 38,47 \\
\hline América Latina & $-26,30$ & 10,28 & 2,92 & 38,66 & $-8,83$ & 55,19 & 32,36 & 44,31 \\
\hline Resto do Mundo & $-11,32$ & 27,43 & 18,88 & 33,05 & $-3,24$ & 52,47 & 35,43 & 39,64 \\
\hline
\end{tabular}

Fonte: Cálculos da pesquisa

As variações das exportações do Brasil são reduzidas com a desvalorização do Peso, mas continuam positivas para todas as regiões. As maiores perdas ocorrem para a América Latina, onde a variação para grãos cairia para cerca de $3 \%$ positivo, e para a China, onde ficariam em $4,84 \%$. Para as exportações de derivados, apesar das quedas relativas ao período anterior, o Brasil permanece com taxas de crescimento expressivas para todas as regiões, sendo a menor delas, perto de $30 \%$, para a China.

\section{Validação do Modelo}

A Tabela 9 mostra as taxas médias anuais de crescimento da produção de soja e das exportações de grãos e derivados, dos três principais exportadores de soja, para a década de 1990 e para o período 1999-2002, anos seguintes à desvalorização do Real e a inclusão dos subsídios aos produtores americanos de soja. 
Tabela 9 - Crescimento anual médio (\%) da produção e exportação de soja e derivados (1990-1999; 2000-2002)

\begin{tabular}{cccccccccc}
\hline & \multicolumn{2}{c}{ Brasil } & \multicolumn{2}{c}{ Argentina } & \multicolumn{2}{c}{ USA } & \multicolumn{2}{c}{ Mundo } \\
\cline { 2 - 9 } & $90-99$ & $99-02$ & $90-99$ & $99-02$ & $90-99$ & $99-02$ & $90-99$ & $99-02$ \\
\hline Produção (grão) & 6,3 & 10,6 & 9 & 15,4 & 4,5 & 0,6 & 4,6 & 4,5 \\
\multirow{3}{*}{ Exportação } & Grão & 22,6 & 22,5 & 32,3 & 32,2 & 6 & 4,6 & 5,1 & 10,3 \\
& farelo & 2,8 & 5,9 & 11,5 & 7,5 & 4,6 & $-6,1$ & 4,6 & 5 \\
& Óleo & 15 & 13,1 & 13,3 & 4,3 & 15,9 & 13,5 & 10,6 & 4,3 \\
\hline
\end{tabular}

Fonte: a partir de dados de FAOSTAT, 2004

A produção de soja no mundo manteve aproximadamente a mesma média de crescimento anual nos dois períodos. Na década de 1990, a produção americana seguiu o crescimento mundial médio, com taxa de $4,5 \%$ ao ano. Brasil e Argentina obtiveram crescimento um pouco superior, $6,3 \%$ e $9 \%$, respectivamente, no mesmo período.

Todos os três países (Brasil, Argentina e EUA) mantêm aproximadamente a mesma taxa de crescimento média de suas exportações de grãos da década de 1990, para o período 1999-2002, com maior variação para os EUA cujo crescimento médio decresceu de $6 \%$ para $4,6 \%$, sendo a Argentina a que obteve maior crescimento.

Para os derivados, eles tiveram seus crescimentos de exportações de óleo reduzidos, acompanhando a diminuição mundial. A redução nas taxas de crescimento para o Brasil e para os EUA foi pequena, diferentemente da taxa da Argentina de crescimento das exportações, que caiu de 13,3\% na década de 1990 para 4,3\% em 1999-2002. Para o farelo de soja, apenas Brasil obteve melhor taxa de crescimento das exportações, de 1999 a 2002, em relação à década de 1990: 5,9 contra 2,8. O crescimento anual médio das exportações de farelo da Argentina caiu de 11,5 para 7,5 no mesmo período. A grande alteração nesse mercado foi a queda expressiva das exportações americanas (-6,1\%) no período posterior a 1999.

Os dados das exportações por destinos, para o período de 1999 a 2002 (disponíveis apenas para o Brasil em USDA, 2003) permitem análise mais detalhada das mudanças recentes ocorridas antes da desvalorização do peso argentino. Ao invés de observar as taxas médias da década, optou-se por comparar os dados dos últimos três anos da década de 1990 (taxas de 1996 a 1999) com as taxas de 1999 a 2002. As 
atribuições de mudanças no mercado devem ser comedidas, uma vez que a desvalorização pode gerar efeitos negativos, inicialmente.

Os crescimentos das exportações brasileiras de grão de soja e seus derivados para o período de 1996 a 1999 (Tabela 10) contrastam com os dados apresentados anteriormente para a década de 1990 (Tabela 9), onde fica evidente o crescimento anormal das exportações de grão do Brasil, de 1996 a 1999, com a volta das taxas anuais de crescimento a patamares similares aos da década de 1990, após $1999^{6}$. Para as exportações de farelo de soja, evidencia-se taxa média de crescimento, no período de 1999-2002, superior a da década de 1990.

Tabela 10 - Crescimento percentual das exportações brasileiras de soja e derivados, por destino, para os períodos anterior e posterior à desvalorização do Real / aumento dos subsídios americanos

\begin{tabular}{lllllll}
\hline & \multicolumn{2}{c}{ Grãos } & \multicolumn{2}{c}{ Farelo } & óleo \\
\cline { 2 - 7 } Destinos & $96-99$ & $99-02$ & $96-99$ & $99-02$ & $96-99$ & $99-02$ \\
\hline EU & $38 \%$ & $9 \%$ & $7 \%$ & $3 \%$ & - & - \\
China & $277 \%$ & $99 \%$ & $-30 \%$ & $-42 \%$ & - & - \\
Leste Asiático & $25 \%$ & $23 \%$ & $11 \%$ & $28 \%$ & $-12 \%$ & $18 \%$ \\
Or. Medio & - & - & - & - & $84 \%$ & $7 \%$ \\
Total & $45 \%$ & $22 \%$ & $-1 \%$ & $6 \%$ & $7 \%$ & $14 \%$ \\
\hline
\end{tabular}

Fonte: a partir de dados de FAOSTAT, 2004

Para grãos, a análise por destino revela que, na comparação dos dois períodos (96-99 e 99-02), o Brasil reduziu seu crescimento de exportações para UE, em relação aos três anos anteriores a 1999, mas manteve-o positivo, e passou a ser, desde 1999, o principal exportador para esse destino (aproximadamente 9 Mt, em 2002). Já a Argentina mantém exportações de grãos irrisórias $(0,4 \mathrm{Mt})$ desde a queda brusca de -68\% de suas exportações para esse destino, de 1999 a 2000. Para a China, os três concorrentes não exportavam quantidades expressivas até meados da década de 1990, quando houve abertura de importações de grãos, justificando as elevadas taxas de crescimento para esse destino a partir de então.

\footnotetext{
${ }^{6}$ Em setembro de 1996, foi sancionada a Lei Kandir, que isentou os produtos primários destinados à exportação, da cobrança do ICMS, sendo a redução dos impostos para o grão exportado de $13 \%$ e para derivados, de $8 \%$.
} 
Destaca-se que a China importou cerca de $10 \mathrm{Mt}$, em 2000, cresceu as importações para 13 Mt, em 2001, e voltou ao patatar de 10 Mt, em 2002. Comparando 2000 a 2002, as exportações brasileiras para a China dobraram em quantidade, o que mostra a conquista de mercado nesse período. Com as previsões de importação em torno de $18 \mathrm{Mt}$, em 2003, as futuras parcelas de cada país mostrarão se houve equilíbrio da competitividade por parte da Argentina, com a desvalorização do Peso. Observa-se que, em 2000, a China importava $68 \%$ das exportações argentinas de grão.

Para o Leste Asiático, Brasil e Argentina exportam pouco (menos de $1 \mathrm{Mt}$ ) desde 1999. Os EUA são os grandes detentores desse mercado (mais de 7 Mt desde 1999). Mas as taxas de crescimento de Brasil e Argentina são positivas desde 1997, enquanto para os EUA a taxa teve média nula de 97 a 99, e ficou negativa em 2000.

Para o farelo de soja, as taxas brasileiras mostraram recuperação na comparação dos dois períodos de três anos. Os EUA praticamente saíram do mercado europeu, com exportações de 0,6 Mt, em 2000, contra 7,9 Mt da Argentina e 7,6 Mt do Brasil (9,1 Mt em 2002). Esse fato é evidenciado, com a queda do percentual das exportações americanas para a UE, que respondiam por $27 \%$ das exportações totais americanas na década de 90 , passando para $9 \%$ em 2000, o que deslocou a UE de principal comprador do farelo dos EUA, na década de 1990, para modesto quinto lugar, em termos de participação do total exportado dos EUA.

A política chinesa de proteção à indústria interna de esmagamento, facilitando as importações de grão e dificultando as de derivados, praticamente eliminou as importações da China de farelo e óleo. Os três maiores exportadores enviavam quantidades em torno de 1 Mt em 1998, com as exportações brasileiras e americanas passando a perto de zero e as argentinas à 0,3 Mt, em 2000. Neste caso, a política chinesa interna prevaleceu sobre as recentes mudanças políticas nos países exportadores. As expectativas são para reduções de suas tarifas, com a entrada do país na OMC, em 2001, e compromisso de redução tarifária até 2005.

Para o Leste Asiático, em 2000, EUA, Argentina e Brasil exportaram 1,7 Mt, 1,5 Mt e 0,5 Mt, respectivamente. Em 2002, o Brasil triplicou suas exportações para esse destino. Como as importações do Leste Asiático não chegaram nem mesmo a duplicar de 2000 para 2002, o Brasil ganhou mercado de seus concorrentes após 1999. 
Para o Oriente Médio, destaca-se a ausência da participação das exportações brasileiras, onde Argentina e EUA exportaram, em 2000, 1,8 Mt e 1,1 Mt, respectivamente. Contudo, tem ocorrido direcionamento da política internacional brasileira para ampliação de relações comerciais com os países dessa região.

Acordos como o NAFTA (entre EUA, México e Canadá) permitem a maior diversificação de destinos para as exportações americanas e asseguram certo mercado cativo. A América Latina (praticamente o México) e o Canadá importam $25 \%$ e $12 \%$ do total exportado de farelo americano, com Brasil e Argentina sem participações nesses mercados.

Para o óleo de soja, Brasil e EUA são países de elevado consumo, sendo a Argentina o maior destaque como exportadora desse produto, na década de 1990. Contudo, o Brasil exportou cerca de 2 Mt de óleo, em 2002, tendo como principais destinos, o Leste Asiático e o Oriente Médio (apesar da participação inexpressiva do Brasil no mercado de farelo). Os EUA praticamente não exportam óleo. Argentina exportou perto de $3 \mathrm{Mt}$, em 2000, mas vem perdendo participação mundial para o Brasil.

Em resumo, no curto prazo, a desvalorização do Real/subsídios americanos asseguram vantagem ao Brasil no mercado de soja, para o grão, farelo e óleo. Esses ganhos são comprovados pelo modelo de equilíbrio geral, no médio prazo. Como a desvalorização argentina só ocorre em 2002, suas taxas de crescimento para os derivados podem recuperar-se nos próximos anos, como mostram os resultados do GTAP. Para os EUA, não se observam, no curto prazo, os bons resultados do modelo de equilíbrio geral para as exportações de grãos, contudo para os derivados, ambas as análises evidenciam perdas de mercado do país.

\section{Conclusões e Discussões}

As estatísticas de curto prazo para o mercado exportador de derivados, confirmam os resultados do GTAP, nos quais o Brasil e a Argentina vêm ganhando participação dos EUA, mas são contrárias ao modelo para as exportações de grãos. Em ambos os prazos, verifica-se taxa negativa de crescimento das exportações americanas para os derivados de soja. No mercado exportador de grãos e de derivados, no cenário 3 (já computada a desvalorização do Peso), o Brasil apresenta aumento das exportações mais elevado que a Argentina. 
Para a UE, o Brasil confirma-se como principal exportador de grãos nas duas análises, com conquista de mercado de ambos os concorrentes. No mercado de farelo, Brasil e Argentina continuam dividindo o mercado europeu, e os EUA praticamente se retiram.

Para a China, as exportações brasileiras de grão cresceram muito após 1999, com a análise de médio prazo indicando essa continuação. A recente proteção chinesa para os derivados de soja não é considerada no modelo de equilíbrio geral, resultando em crescimento das exportações de farelo de Brasil, que está condicionada a futuras mudanças políticas na China.

No mercado do Leste Asiático, os resultados do modelo indicam ganhos percentuais expressivos para o Brasil, mas os EUA, até 2002, ainda permaneciam como o principal exportador de grãos para a região. Contudo, para os derivados de soja, o Brasil confirma os elevados percentuais de médio prazo, triplicando suas exportações de 1999 a 2002.

$\mathrm{O}$ acordo do NAFTA beneficia as exportações dos EUA para a América Latina e Canadá. Os aumentos percentuais nas exportações de Brasil, no GTAP, são altos, mas incidem sobre quantidades muito pequenas.

Esses resultados levam em consideração apenas as últimas mudanças ocorridas, sem contar com outras questões importantes para o mercado da soja. Na modelagem de médio prazo, a hipótese de Armington (diferenciação de produtos pela origem) não considera diretamente a distinção entre produtos geneticamente modificados. Os EUA e a Argentina têm em torno de $75 \%$ e $95 \%$ de sua produção na forma transgênica (Huerta \& Martin, 2002; Hillcoat \& Guibert, 2002) restando o Brasil como a última fronteira de soja não transgênica. As desvantagens de custos dos produtores da região Sul em relação aos argentinos e paraguaios são claras, restando aderir aos transgênicos ou sair do mercado, a não ser que os não transgênicos recebam um preço mais elevado, compensando as diferenças. Apesar de argumentos favorecendo a soja não transgênica na UE, as exportações do Brasil e da Argentina têm aumentado para esse destino, mostrando que a UE não parece disposta a pagar um prêmio para não transgênicos, em particular para farelo de soja (insumo para ração animal).

Para a China e outros países do Leste Asiático, os trangênicos não parecem ser um complicador para o comércio. Ao contrário, custos e preços 
são variáveis chaves para determinar os fluxos de mercado. Apenas se uma mudança não prevista no mercado mundial ocorrer, a soja geneticamente modificada será absoluta, previsão feita há muitos anos por Norman Borlaug, o que aumentaria ainda mais a vantagem brasileira com o aumento de produtividade e redução de custos da soja transgênica.

Do lado da demanda dois pontos são decisivos: 1) como previsto por IFPRI (Delgado et $\boldsymbol{a l}$., 1999) haverá grande necessidade de proteína animal em 2020, dado o crescimento de renda no mundo e a tendência de consumo de proteína mais cara, sendo a soja insumo importante para a ração animal; 2) estabilidade econômica e política e crescimento populacional na Ásia estão transformando os países asiáticos, em particular a China, em alguns dos melhores compradores do mundo. Os EUA já ocupam quase toda sua área adequada e seus altos custos de produção requerem altos subsídios. A Argentina também está quase atingindo seu limite, tendo ocupado a maior parte da área agrícola adequada (Hillcoat \& Guibert, 2002). O Brasil é a última grande fronteira produtiva para expansão da soja, podendo as políticas internas e investimentos em infra-estrutura frear ou apoiar a expansão. Há uma preocupação ambiental em relação à expansão para o Norte e para a Amazônia, mas existem ainda possibilidades de expansão para o Centro-Oeste: Estados do Mato Grosso, Goiás e Tocantins (Bertrand, 2001); e para o Nordeste, à Sudeste do Piauí; áreas já parcialmente ocupadas com soja.

Os subsídios americanos devem continuar, apesar das queixas de Brasil e Argentina. Apesar disso, a participação americana deve continuar caindo. Também não há mudanças previstas para o mercado europeu. A China adotou tarifas para farelo e óleo, favorecendo importações de grãos, mas pressões maiores na OMC são esperadas, com sua proteção devendo ser reduzida.

Concluindo, parece que uma expansão do mercado deve favorecer a produção nos países do Mercosul e o consumo nos países em desenvolvimento. Medidas de liberalização comercial podem favorecer as exportações de derivados de soja sobre o grão, permitindo uma maior agregação de valor nos países exportadores. 


\section{Referências bibliográficas}

Bertrand, J. P., G. Hillcoat, M. Guibert, H. Thery, P. Waniez, N. Mello, S. Souchaud. Les principaux facteurs de la compétitivité des filières céréales et oléo-protéagineux au Brésil et en Argentine: politiques des états et stratégies des acteurs. Relatório final coordenado por Bertrand. Publicação do Institut National de la Recherche Agronomique - INRA. Nogent-sur-Marne, France, 423 p. 2001.

Brandão A. S. P. \& E. C. R. Lima. Impacts of the U.S. subsidy to soybeans on Brazilian production and exports. Trabalho encomendado pelo Ministério da Agricultura e do Abastecimento e pela Confederação Nacional da Agricultura (CNA). Versão preliminar. Rio de Janeiro. Agosto, 2002.

Caves R. E., J. A. Frankel \& R. W. Jones. Economia Internacional: Comércio e Transações Globais. Ed. 8, Editora Saraiva. 2001.

Coelho, C. N. A Lei Agrícola Americana de 2002. Cadernos de Ciência \& Tecnologia, Brasília, v. 19, n.3, p. 473-483. Set./dez., 2002.

Costa, E. F. Brazil's New Floating Exchange Rate Regime and Competitiveness in the World Poultry Market. Journal of Agricultural and Applied Economics 33, 2, p. 367-375. 2001.

Delgado, C., M. Rosegrant, H. Steinfeld, S. Chui \& C. Courbois. Livestock to 2020: The Next Food Revolution. Discussion Paper 28, IFPRI. 1999.

Figueiredo A. M. R., A. V. Ferreira, E. C. Teixeira. Impactos da Integração Econômica nas Commodities da Economia Brasileira e da União Européia. Revista Brasileira de Economia (RBE). Rio de Janeiro, FGV, v. 55(1), p. 77-106. Jan./mar., 2001.

FAOSTAT. Food and Agriculture Organization of the United Nations. FAO Statistical Databases. http://www.apps.fao.org. 2004.

Grennes, Thomas. International Economics. Englewood Cliffs, NJ: Prentice-Hall, Inc. 1984.

Gurgel, A. C., M. B. Bitencourt, E. C. Teixeira. Impactos dos Acordos de Liberalização Comercial ALCA e Mercoeuro sobre os Países Membros. 
Revista Brasileira de Economia (RBE). Rio de Janeiro, FGV, v. 56(2), p. 335-369. Abri./jun., 2002.

Hertel, T. W. Global Trade Analysis, Modeling and Applications. Editado por Thomas Hertel. Cambridge University Press. 1997.

Hillcoat, G.\& M. Guibert. L'Agriculture pampeenne face a la crise: lês atouts d'une compétitivité acquise et d'une capacité d'adaptation certaine. Relatório do CIRAD. 2002.

Houck, James P. Elements of Agricultural Trade Policies. Prospect Heights, IL: Waveland Press, Inc. 1986.

Huerta, A. I. \& A. M. Martin. Soybean Production Costs: An Analysis of the United States, Brazil and Argentina. AAEA Annual Meeting. Long Beach, CA. 2002.

IPEA. Instituto de Pesquisas Econômicas e Aplicadas. http://www.ipeadata.gov.br/ipeaweb.dll. Acessado em 2002, 2003 e 2004. 2004.

Lower, M. E. Brazil Oilseeds and Products Annual 2002. USDA Foreign Agricultural Service, FAS, GAIN Report. 2002.

Ministério de Economia da República Argentina. Indicadores Econômicos. Site: http://www.mecon.gov.br. 2004.

OECD. Organisation for Economic Co-operation and Development. Agricultural Outlook 2000-2005, Paris. 2000.

USDA. Departamento de Agricultura dos Estados Unidos. Economic Research Service (Programa desenvolvido por Karl Gudmunds), http:// www.usda.gov. 2003.

USDA. 2002 Census of Agriculture. http:/www.nass.usda.gov/census. 2004.

Verdonk, R. Brazil Oilseeds and Products Annual 2003. USDA Foreign Agricultural Service, FAS, GAIN Report. http://www.fas.usda.gov/ scriptsw/attacherep/default.asp. 2003.

Westcott, P. \& M. J. Price. Analysis of the U.S. Commodity Loan Program with Commodity Loan Provisions. Economic Research Service/ USDA, Agricultural Economic Report n. 801. Abril, 2001. 
Westcott, P. C. \& M. Prince. Impacts of the US Marketing Loan Program for Soybeans. Oil Crops Situation and outlook/OCS, Economic Research Service/USDA. 1999.

Yu W. \& S. E. Frandsen. China's WTO Commitments in Agriculture: Does the Impact Depend on OECD Agricultural Policies? $5^{\text {th }}$ Annual Conference on Global Economics Analysis, Taipei and International Conference on China and the World Economy, Hong Kong. 2002.

Recebido em agosto de 2004 e revisto em abril de 2006 